\title{
Portugiesische Redewendungen - Fraseologia para aprendizes de L. E.
}

\section{Nara C. Sanseverino Mahler}

Stefan Ettinger e Manuela Nunes: Portugiesische Redewendungen - Ein Wörter- und Übungsbuch für Fortgeschrittene. Helmut Buske Verlag Hamburg, 2006. 151 páginas. ISBN 3875484398

Quando do estudo de uma língua estrangeira, uma questão que se nos apresenta como crucial é o aprendizado do léxico dessa língua. Afinal, como se consegue adquirir um vocabulário tal, que nos permita uma comunicação satisfatória nos vários graus de conhecimento pelos quais devemos passar? $\mathrm{Na}$ medida em que vamos nos aprofundando no estudo de uma língua, vamos também nos deparando com estruturas lingüísticas mais complexas, como aquelas corriqueiramente conhecidas como "expressões idiomáticas", as quais não podem ter seu significado inferido pela simples transposição de cada um de seus componentes para nossa língua materna. Além disso, não basta apenas conhecer seu significado, é preciso conhecer também as situações em que podem ser empregadas, para que o falar possa se constituir num ato comunicativo eficiente.

A fim de contribuir para o estudo e compreensão dessas expressões, são elaborados dicionários especializados e glossários, assim como obras que tratam de fraseodidática. Poucos, porém, são os trabalhos que procuram encontrar expressões correspondentes entre o alemão e o português. O recente trabalho de Stefan ETTINGER e Manuela NuNES - Portugiesiche Redewendungen - Ein Wörter-und Übungsbuch für Fortgeschrittene surge como uma nova contribuição, na medida em que se constitui não somente num dicionário de fraseologismos, mas também em um livro de exercícios, onde 250 expressões selecionadas pelos autores podem ser trabalhadas pelo aprendiz.

Preliminarmente, são apresentadas algumas observações importantes para que se possa melhor aproveitar e manusear o dicionário, definido pelos autores como "uma seleção de expressões idiomáticas, voltada não só para

\footnotetext{
* Mestranda do Programa de Pós-graduação em Língua e Literatura Alemã da Universidade de São Paulo.
} 
estudantes avançados de português que desejem aprofundar seus conhecimentos lingüísticos, como também para falantes de língua portuguesa, vivendo na Alemanha, interessados em estudos comparativos de tais expressões.” (p. 7). A obra pretende também dar sua contribuição enquanto ferramenta complementar em cursos de língua,possuindo, para tanto, uma parte denominada “Quizaufgaben".

Apesar de considerarem ser o português uma língua extremamente rica em expressões idiomáticas (uma das mais ricas, ressaltam os autores), foram selecionados apenas 250 fraseologismos, número esse justificado pelo fato de se haver dado preferência apenas a expressões que:

1) não carregassem em si peculiaridades regionais;

2) expressassem relacionamentos humanos em geral;

3) fossem conhecidas na Europa pela cultura cristã-judaica;

4) demonstrassem algumas particularidades da vida social portuguesa;

5) ilustrassem fatos de cultura e costumes;

6) ilustrassem o fino humor da língua portuguesa e, por último,

7) fossem utilizadas, sem problemas, tanto na escrita quanto na fala corrente de portugueses e brasileiros.

Ainda com respeito aos critérios de seleção, ETTINGER e NUNES esclarecem que evitaram tanto as expressões mais eruditas, utilizadas em textos literários, como também as mais vulgares, concentrando sua busca na linguagem informal do dia-a-dia (linguagem corrente, segundo a classificação encontrada em SCHEMANN 1979) ou em textos jornalísticos.

Passando para as instruções sobre a metodologia a ser seguida, o usuário é orientado a tentar compreender a imagem da expressão, com a ajuda de dicionários mono ou bilíngües; uma situação ideal seria aquela em que o aprendiz pudesse ser acompanhado por um professor falante nativo de português, a fim de que eventuais dúvidas acerca de particularidades da língua (sinônimos, antônimos, formação de diminutivo, etc.) pudessem ser esclarecidas.

Após a transcrição do fraseologismo, encontramos seu significado em português e, em seguida, em alemão. No caso de haver uma expressão idiomática equivalente em alemão, ela é transcrita logo a seguir, como no exemplo adiante: 
60 Fazer algo no dia de São Nunca (à tarde)

(cf. fazer algo quando as galinhas tiverem dentes)

nunca

etwas niemals tun; etwas am Sankt-Nimmerleins-Tag tun;

etwas tun, wenn Oster und Pfingsten auf einen Tag fallen (ugs.)

São sugeridas, também, formas de se trabalhar com os "Quizübungen", os quais podem ser utilizados pelos aprendizes tanto em conjunto com outros alunos em cursos de língua, quanto em casa, praticando sozinhos.

Ao final da introdução, ETTINGER e NunES manifestam seu desejo de que o trabalho possa contribuir para a aquisição de sólidos conhecimentos acerca de expressões idiomáticas representativas do português, assim como despertar um interesse maior sobre o estudo das expressões fraseológicas da língua, o que, por si só, já terá satisfeito o objetivo da obra.

\section{Falando um pouco de Fraseologia}

O que é uma expressão idiomática? Com essa pergunta, os autores prosseguem na tentativa de despertar no leitor a curiosidade do aprendizado desse campo tão complexo no aprendizado de uma língua. Parte-se da expressão "estar com a faca e o queijo na mão", para tentar definir o que se entende por "expressão idiomática". Ao traduzir palavra por palavra, chegaríamos a um quadro onde alguém está segurando uma faca numa das mãos e um queijo na outra, pronto para cortá-lo. No entanto, os falantes nativos da língua portuguesa sabem que essa expressão significa que esse alguém tem condições de impor sua vontade o que, em alemão, corresponderia a "alle Macht baben; alle Trümpfe in der Hand haben." $\mathrm{Na}$ expressão em português, temos um verbo (estar) ligado a dois substantivos (faca e queijo). Apesar de o verbo poder ser conjugado no plural, os substantivos da expressão só podem aparecer no singular, visto que dizer "eles estão com as facas e os queijos nas mãos" não teria mais o mesmo sentido. Assim, uma expressão idiomática tem um certo grau de fixidez e pode quase sempre ter dois significados: um literal e um figurado. Quase sempre, porque em "falar pelos cotovelos" não se pode encontrar um sentido literal. Portanto, uma expressão idiomática não pode ser considerada como a soma do significado de seus constituintes e é exatamente a incongruência entre o significado geral de uma expressão e a soma dos significados dos seus lexemas que possibilita aos aprendizes reconhecer uma ainda desconhecida expressão, como expressão idiomática. Num contexto em que pessoas estejam sentadas à mesa, o significado literal 
de "estar com a faca e o queijo na mão" é perfeitamente cabível; em outro contexto que não inclua situações à mesa, apenas o significado metafórico faz sentido.

A respeito da terminologia adotada, os autores preferiram utilizar a denominação "Redewendungen" (aqui traduzida como "expressão idiomática"), embora na literatura especializada sejam encontrados mais freqüentemente os termos fraseolexema, unidade fraseológica, expressão fraseológica e fraseologismos.

Ainda sobre fraseologia em língua portuguesa, o livro faz um pequeno resumo das pesquisas realizadas até o momento, citando SCHEMANN, HUNDT, PÖll, MOURA, CAMARgo \& BORnBusCH, além da própria Manuela Nunes.

As seleções de fraseologismos encontradas na maioria desses trabalhos tentam dar conta de um inventário frasêmico de uma determinada língua, sem contudo possuir a almejada perfeição didática, que possibilite ao aprendiz a aquisição de tais expressões em aulas de língua estrangeira. Tais seleções não se aprofundam na questão do uso, ou seja, raramente indicam em que ocasiões a expressão pode ser utilizada, podendo causar danos à comunicação e mal-entendidos. O dicionário em questão aponta para uma possível solução sob este aspecto, uma vez que no "Quizaufgabe" o aprendiz tem a oportunidade de testar seu conhecimento não só no que se refere ao significado de uma determinada expressão, como também aos contextos em que ela pode ser empregada.

Nesse ponto, é preciso que se tenha uma visão realista acerca da diferença que existe entre uma competência fraseológica passiva e uma competência fraseológica ativa. Isso porque um aprendiz pode muito bem saber o que significa "abotoar o paletó" (competência passiva) e cometer o erro de utilizá-la, por exemplo, no funeral de alguém (competência ativa). Se os fraseologismos podem ser definidos como o "tempero de uma língua", assim como na cozinha, se você sabe como utilizar bem esses temperos, o resultado será um bom desempenho lingüístico.

Os autores sugerem a confecção de uma "Folha de Trabalho", elaborada com o objetivo de que os aprendizes possam aprofundar seus estudos em relação ao conhecimento e compreensão das expressões idiomáticas arroladas no dicionário. Da maneira como foi organizada, parecenos que essa folha de trabalho pode se tornar uma importante ferramenta para aqueles que desejem aprofundar seus conhecimentos a respeito do assunto, já que ela conduz o aprendiz a uma reflexão mais detalhada sobre os fraseologismos que ele mesmo selecionou como objeto de estudo. 
Em relação ao dicionário propriamente dito, após pesquisa realizada no site de busca "Google", pudemos constatar que nem todas as expressões selecionadas por ETTINGER e NUNES são de uso corrente no português do Brasil. Das 250 expressões, 133 são utilizadas por falantes brasileiros, sendo que algumas delas apenas por grupos sociais restritos (ex.: pessoas mais velhas). Descontando o número de expressões que são raramente usadas (17), temos um resultado total de 116 fraseologismos usados por falantes brasileiros, ou seja, menos da metade das expressões arroladas. Por esse motivo, fica prejudicada a afirmação dos autores de que as expressões constantes do dicionário fariam parte da linguagem corrente tanto de portugueses quanto de brasileiros, o que pode levar os aprendizes do português a incorrerem em erros interpretativos de textos, assim como a mal-entendidos na comunicação. Se alguém disser aqui no Brasil "Ontem o João visitou as capelinhas", nenhum falante nativo vai compreender que João andou de bar em bar, consumindo álcool.

Outro problema verificado, seria quanto à forma das expressões utilizadas no Brasil e em Portugal. Muitas delas foram modificadas no português do Brasil e o consulente não encontra essa informação nas entradas do dicionário. Faltam as informações sobre estilo e marca de registro, informações essas muito importantes para a competência ativa do aprendiz.

Apesar dos problemas ressaltados anteriormente, é de se reconhecer a grande relevância do trabalho de ETTINGER e NUNES, no sentido de contribuir para a pesquisa de fraseologia e fraseodidática, além de se constituir numa importante ferramenta para aqueles interessados em sugestões para $o$ ensino da fraseologia de línguas estrangeiras. Sob esse último aspecto, e considerando a escassez de trabalhos semelhantes, pode-se dizer que este dicionário se constitui, para os falantes de português, (quase) numa luz no fim do túnel. 